\title{
Hourly Solar Radiation Estimation Using Ambient Temperature and Relative Humidity Data
}

\author{
Dimas Firmanda Al Riza, Syed Ihtsham ul Haq Gilani and Mohd. Shiraz Aris
}

\begin{abstract}
This paper presents hourly solar radiation estimation methods using ambient temperature and relative humidity data. The methods are based on the decomposition model that is calculating each of solar radiation components, which depend on atmospheric transmittance. Two methods to predict atmospheric transmittance value using available meteorological data were proposed. In the first method, a decision matrix was used, while in the second method, regression correlation of meteorological parameters was used. The calculations results were evaluated using statistical parameter. Though the result shows both of the methods perform well, more satisfactory results were obtained from first method with Root Mean Square Error of $87.6 \mathrm{Watt} / \mathrm{m}^{2}$, Normalized Root Mean Square Error of $8.29 \%$, correlation coefficient of 0.95 and index of agreement of 0.97 . Furthermore, the first method only needs ambient temperature and relative humidity data that commonly measured in meteorological stations.
\end{abstract}

Index Terms-Decomposition method, hourly solar radiation estimation, meteorological method, data filling.

\section{INTRODUCTION}

Time series solar radiation data is important for modeling and design of solar radiation related devices or systems, such as photovoltaic (PV) system. Hence, complete time series data is significant for performance prediction and other purposes. However, this solar radiation data are not always available for every area, even if there is a weather station near the area, the data access often limited. Furthermore, the data available data may contain missing data for several days in the absence of measurement. Sometimes this missing data only occurred for some parameter in meteorological data set, while other parameters are complete data. This might happen due to sensor error or damage. Therefore, an estimation method is required to fill the missing data. This paper is focusing on hourly solar radiation estimation method using ambient temperature and relative humidity data.

Manuscript received May 24, 2011. This work was supported in part by the UTP Short Term Internal Research Funding. Hourly Solar Radiation Estimation Using Ambient Temperature and Relative Humidity Data. Dimas Firmanda Al Riza, Syed Ihtsham ul Haq Gilani, Mohd. Shiraz Aris.

D. F. Al Riza is with the Mechanical Engineering Department, Universiti Teknologi PETRONAS, Bandar Seri Iskandar, Perak, Malaysia (e-mail: dimasfirmanda@yahoo.com).

S. I. Gilani, is with the Mechanical Engineering Department, Universit Teknologi PETRONAS, Bandar Seri Iskandar, Perak, Malaysia (e-mail: syedihtsham@petronas.com.my).

M. S. Aris, is with the Mechanical Engineering Department, Universit Teknologi PETRONAS, Bandar Seri Iskandar, Perak, Malaysia (e-mail: mshiraz_aris@petronas.com.my).
There are various methods to estimate solar radiation. Satisfactory result for hourly solar radiation estimation was obtained by using atmospheric transmittance model [1] while other authors have used diffuse fraction [2] and clearness index models [3]. Parametric or atmospheric transmittance model requires details atmospheric characteristic information [4]. This model gives high-accuracy for clear sky/cloudless conditions, which is leading some author to use this model to evaluate the performance of an empirical model under cloudless conditions [5]. There are numerous authors proposed this kind of model as mentioned in [6]. However, pure parametric model was not used in this study, since there is no detail atmospheric condition data for the site.

Meteorological parameters frequently used as predictors of atmospheric parameters since acquiring detail atmospheric conditions require advance measurement. Meteorological parameters such as sunshine duration, cloud cover, ambient temperature, relative humidity, and precipitation data have been used to estimate atmospheric transmittance coefficient in parametric model. This kind of model is called meteorological model.

Global solar radiation estimation from the sunshine duration was initiated by Angström [7] and following by other researchers such as those which mentioned by [8]. Bristow and Campbell [9] and Hargreaves and Samani [10] proposed solar radiation estimation using the differences between maximum and minimum ambient temperature. Some studies also add measured precipitation to the temperature based hourly solar radiation prediction, and the methods are claimed to perform well $[11,12]$. Among the methods above, there are authors who have proposed to estimate directly total global radiation using meteorological parameter, and then the calculation of the beam and diffuse radiations are carried out using the decomposition model.

Not all of hourly solar radiation estimation methods can be applied due to the non-availability of the data in the area. In this paper missing data of solar radiation was estimated using two methods, first, beam atmospheric transmission determination with measured $\mathrm{RH}$ and ambient temperature data and second method using RH-beam transmittance correlation through clearness index-beam transmittance correlation. Several authors proposed clearness index-beam transmittance numerical correlation based on data in certain areas $[13,14]$. In this paper clearness index-beam transmittance numerical correlation was proposed using measured data in Universiti Teknologi PETRONAS, Bandar Sri Iskandar.

Statistical parameters were used to validate the estimation results. Once the result is validated, it can be used to fill missing solar radiation data in the data set with confidence. 
With this data filling, complete hourly time series solar radiation is obtained and can be used for any purpose such as PV system performance prediction.

\section{DATA SET}

In this research Ipoh city weather data was used as a study case. The data contain 5 (five) parameters that recorded hourly through year 2003 . The parameters are solar radiation, ambient temperature, relative humidity, speed and direction of the wind. In the data set, there are 23 days missing solar radiation data while other parameters were complete data set. Ambient temperature and relative humidity data were chosen to estimate solar radiation.

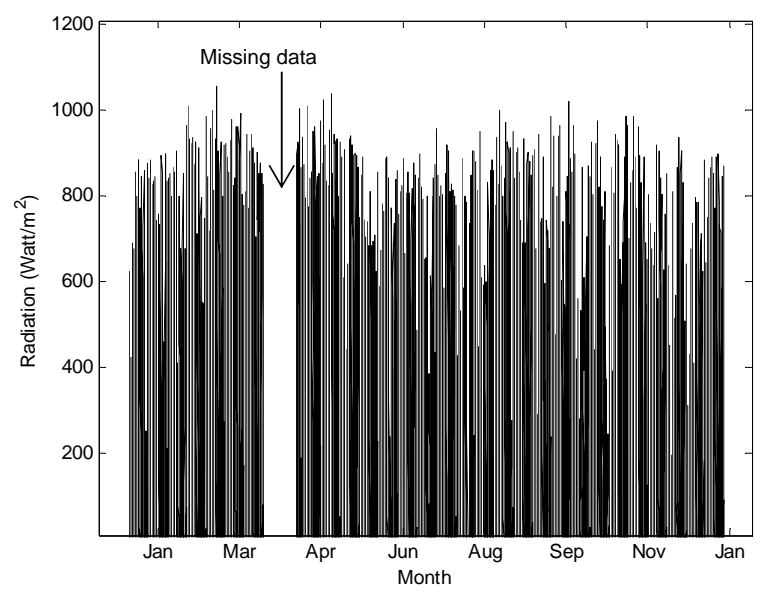

Figure 1: One year hourly solar radiation data with 23 days missing data
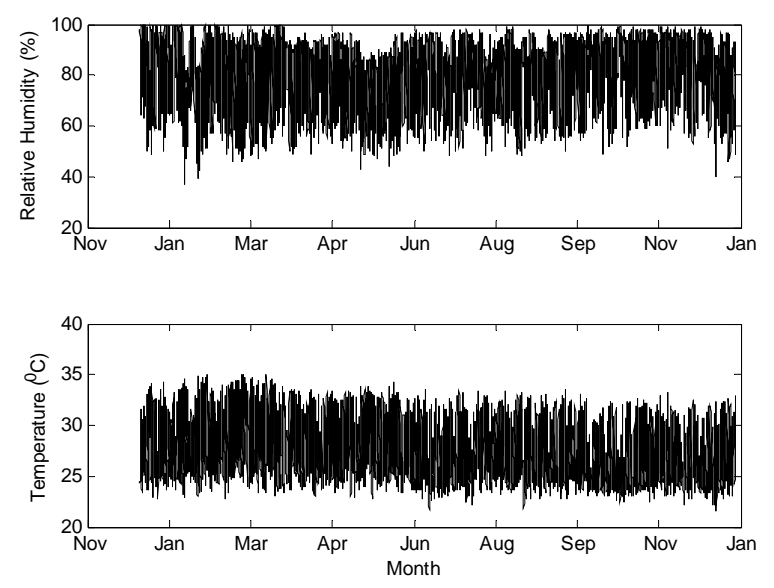

Figure 2: Complete hourly data of RH and ambient temperature

\section{MisSSING DATA ESTIMATION APPROACH}

There are various ways to estimate solar radiation on certain area on the earth. Ambient temperature based estimation is widely used since ambient temperature data are measured in many weather stations. In this study, missing data were estimated based on ambient temperature measurement and used measured RH data as atmospheric transmittance determination criteria. The procedures developed by Kurt and Spokas method [12] that estimate hourly solar radiation based on developed Campbell and Norman method [1], was adapted in this study.

Firstly, in this method total radiation energy from the sun can be separated into two basic components: direct beam radiation $\left(G_{B h}\right)$ and diffuse solar radiation $\left(G_{D h}\right)$. The summation of these two components is the total incident solar radiation $\left(G_{T h}\right)$ and represented by:

$G_{T h}=G_{B h}+G_{D h}$

The local intensity of solar beam radiation is determined by the angle between the direction of the sun's rays and the earth's surface. The location of the sun is given by the angle between the sun location and the normal to the surface, referred to as the zenith angle $\left(\theta_{z}\right)$. Zenith angles vary temporally and geographically but are a function of the time of day, latitude, and time of year given by the following relationship [15]:

$\cos \left(\theta_{z}\right)=\sin (\phi) \sin (\delta)+\cos (\phi) \cos (\delta) \cos (\omega)$

To calculate horizontal beam radiation, the following equation was used:

$G_{B h}=G_{P h} \cos \left(\theta_{z}\right)$

$G_{P h}$ is beam radiation received on perpendicular surface to incoming radiation. The model chosen for the $G_{P h}$ is from Liu and Jordan [16], where the beam radiation $\left(G_{B h}\right)$ is given by:

$G_{P h}=G_{o h} \tau^{m}$

$G_{o h}$ is the solar constant $\left(1,360 \mathrm{~W} / \mathrm{m}^{2}\right), \tau$ is the atmospheric transmittance, and $m$ is the optical air mass number. The optical mass number $(m)$ is found from the following relationship [1]:

$m=P_{a} / 101.3 \cos \left(\theta_{z}\right)$

$P_{a}$ being the atmospheric pressure $(\mathrm{kPa})$ at the site and the zenith angle from Equation 3.40. Average barometric pressure was estimated from the relationship [1]:

$P_{a}=101.3 e^{-(a / 8200)}$

$a$ is the elevation of the site (meters).

However, not all of the beam radiation reaches the earth's surface. Radiation is reflected or absorbed by atmospheric gases, clouds, and dust particles. Some of this radiation is scattered toward earth and is referred to as diffuse radiation $\left(G_{D h}\right)$. Campbell and Norman [1] devised an empirical relationship based on work of Liu and Jordan [16] for an estimation of diffuse radiation. This relationship is given by:

$G_{D h}=0.30\left(1-\tau^{m}\right) G_{0 h} \cos \left(\theta_{z}\right)$

\section{ATMOSPHERIC TRANSMITTANCE ASSIGNMENT PROCEDURE}

The key for the accuracy of above method is in the determination of beam atmospheric transmittance $(\tau)$. Beam atmospheric transmittance is the percentage of the beam (direct) radiation that will penetrate the atmosphere without being scattered. Kurt and Spokas [12] used precipitation data to built decision matrix of atmospheric transmittance.

Gueymard C. [6] stated that if precipitation data were not available and the value estimated from ground data of temperature and humidity, separate tests have revealed that the instantaneous error in precipitation may will be $>100 \%$, depending on atmospheric conditions and on the 'universality' of the empirical model used. Therefore, 
although we do not have precipitation data, in this study we do not intend to predict precipitation value by using available temperature and humidity data. In this study, two methods of beam atmospheric transmittance assignment procedure were proposed as follows:

\section{A. Method 1}

The first method is using the same approach of Kurt and Spokas by built a decision matrix. The difference is the beam transmittance assignment in this matrix is controlled by Relative humidity value. Better estimation was obtained with the concept that water vapor by mean of $\mathrm{RH}$ reduce the incoming radiation. Kurt and Spokas suggest the value of $\tau$ was modified if $\Delta \mathrm{T}<10^{\circ} \mathrm{C}$ by the following relationship assumed that the site was not near the poles as described by [12]:

$\tau^{\prime}=\tau /(11-\Delta \mathrm{T})$

In first method limitation of $\Delta \mathrm{T}$ was adjusted, above equation was used for $\Delta \mathrm{T}<8^{\circ} \mathrm{C}$. Table 1 shows criteria for the decision of $\tau$ value. $\tau$ value of 0.6-0.7 are commonly used for clear sky atmospheric transmittance coefficient value. In this study $\tau$ value of 0.69 was used for clear sky, assumed that the clear sky condition occurred when $\mathrm{RH}<40 \%$ and ambient temperature more than $8^{\circ} \mathrm{C}$. Calculation algorithm was built based on decision matrix and the $\tau$ value was locally determined using the training of data set to get minimum error. Fig. 3 shows flowchart of method 1 .

TABLE I. ATMOSPHERIC TRANSMITTANCE COEFFICIENT DETERMINATION USING MEASURED RH

\begin{tabular}{|c|c|c|}
\hline No & RH condition (\%) & $\boldsymbol{\tau}$ value \\
\hline 1 & $\mathrm{RH} \leq 40$ & 0.69 \\
\hline 2 & $40<\mathrm{RH} \leq 45$ & 0.67 \\
\hline 3 & $45<\mathrm{RH} \leq 55$ & 0.57 \\
\hline 4 & $55<\mathrm{RH} \leq 65$ & 0.47 \\
\hline 5 & $65<\mathrm{RH} \leq 75$ & 0.41 \\
\hline 6 & $75<\mathrm{RH} \leq 80$ & 0.3 \\
\hline 7 & $\mathrm{RH}>80$ & 0.2 \\
\hline
\end{tabular}

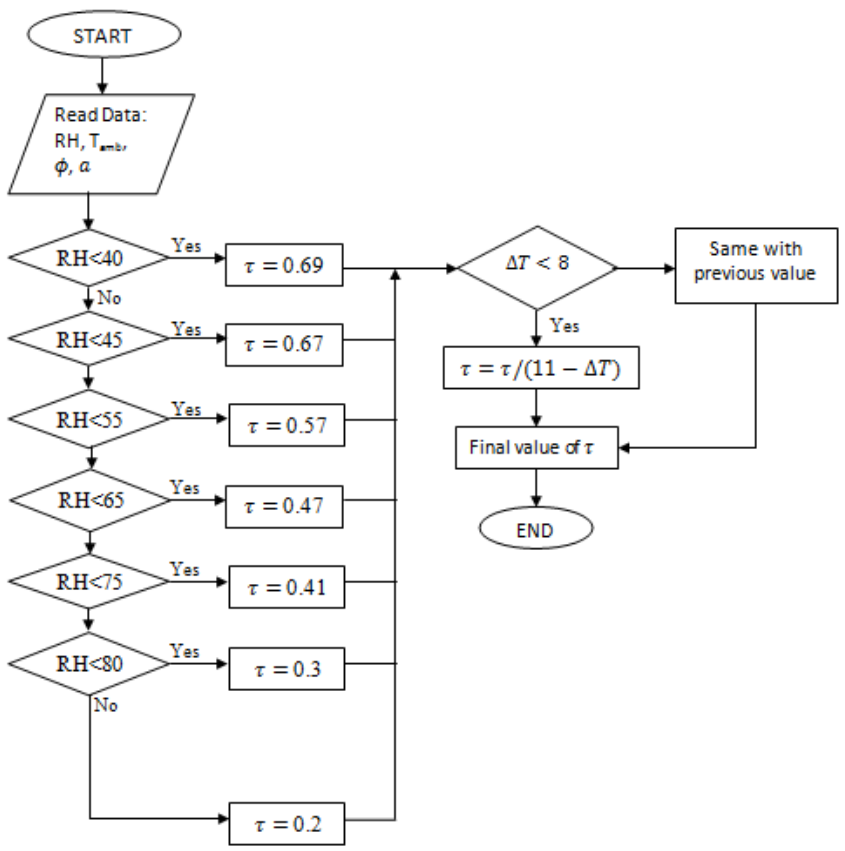

Figure 3: Flow chart to determine beam transmittance for Method 1

\section{B. Method 2}

The second method used in this study is by finding the correlation between $\mathrm{RH}$, clearness index and beam transmittance. The data used to find correlation between beam transmittance and clearness index is measured data from new radiometer set that was installed in 2010 on the rooftop of Block P, Universiti Teknologi Petronas, which located about $30 \mathrm{~km}$ from Ipoh city. About 1 month, 5 minutes time step data of global, beam and diffuse radiation from June to July 2010 was used. Before find the correlation of beam transmittance and clearness index, RH-clearness index correlation was obtained from Ipoh city available data as can be seen in Fig. 4.

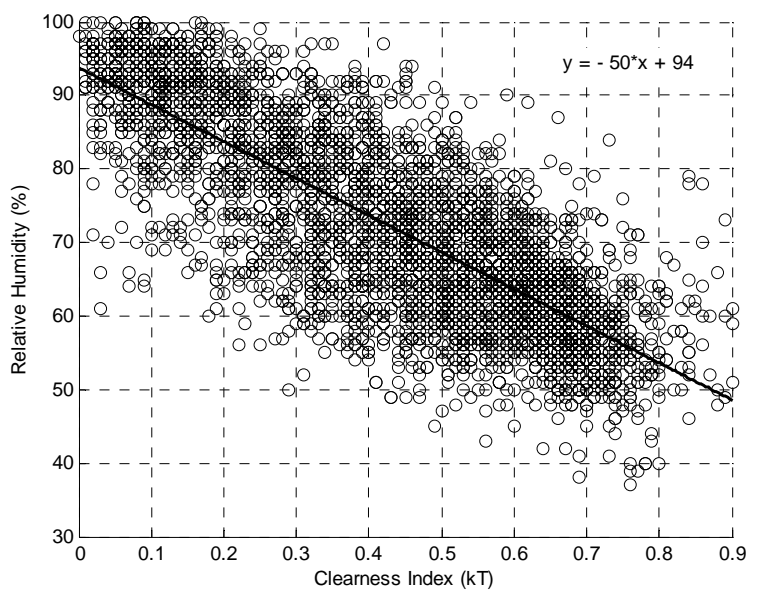

Figure 4: Relative humidity-Clearness Index scatter plot

Then beam transmittance-clearness index correlation can be obtained by scatter plot as can be seen in Figure 4. To plot Fig. 5 some data were rejected due to obvious error that can be analyzed from measurement results, and the basic concept of terrestrial solar radiation characteristics.

Following constraint were used as data rejection criteria:

- Reject night data

- Reject data if clearness index $>1$

- Reject data if beam transmittance $>1$

- Reject data if beam transmittance $>$ clearness index

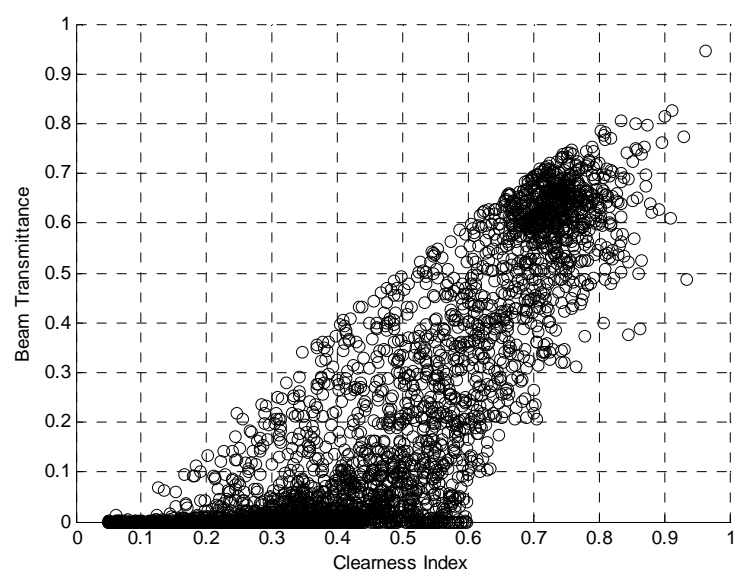

Figure 5: Beam atmospheric transmittance-Clearness Index scatter plot from measurement data in UTP

Correlation between $\mathrm{RH}$ and beam transmittance was obtained from above correlation and plotted in Fig. 6. Balaras 
et al studied the relationship between beam transmittance and clearness index in Athens, Greece [17], the results of the study was adopted to carry out second method in this study. Regression results were presented as follows:

$$
\begin{array}{ll}
\text { Linear } & : \tau=-0.019 \mathrm{RH}+1.576 \\
\text { Quadratic } & : \tau=0.00075 \mathrm{RH}^{2}-0.12676 \mathrm{RH}+5.36 \\
\text { Cubic } & : \tau=0.0000072 \mathrm{RH}^{3}-0.0008 \mathrm{RH}^{2}-0.016 \mathrm{RH}+2.7
\end{array}
$$

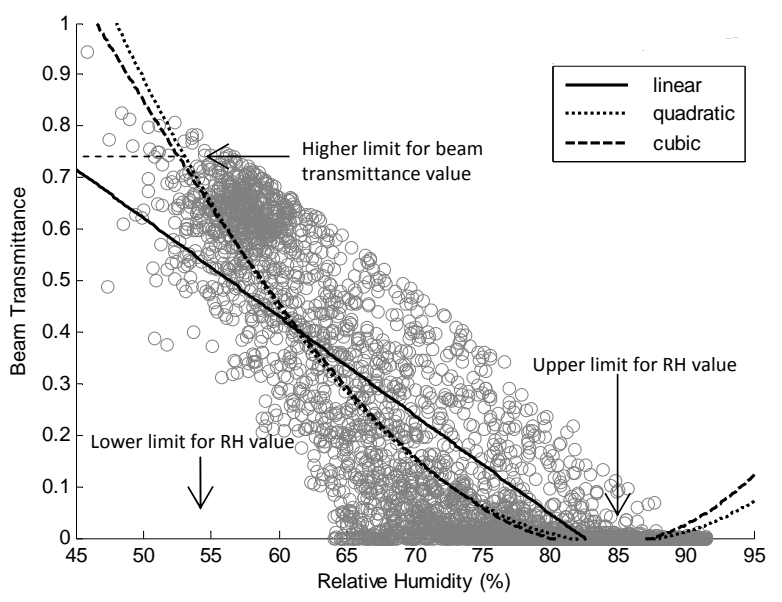

Figure 6: Linear, quadratic and cubic regression results of Beam transmittance vs RH with limitation

In fitting a polynomial to a set of data pairs, it is possible to determine the necessary degree of the polynomial by study of the scatter diagram and get the higher correlation coefficient with the higher polynomial degree. S.M. Ross [18] emphasize that one should always use the lowest possible degree that appears to adequately describe the data. Thus, for instance, whereas it is usually possible to find a polynomial degree $n$ that passes through all the $n$ pairs $\left(\mathrm{x}_{\mathrm{i}}, \mathrm{y}_{\mathrm{i}}\right), \mathrm{i}=1, \ldots n$, it would be hard to ascribe much confidence to such a fit. That is why in this study, the regressions were limited to the cubical or third degree.

\section{Existing method for comparison}

Results of the new model then compared with the existing temperature-based solar radiation prediction model as follow:

\section{a. H-S model}

Hargreaves and Samani [22] conducted an initial study on using $\mathrm{T}_{\max }$ and $\mathrm{T}_{\min }$ to estimate solar radiation by the following equation:

$G_{T h}=K_{r}\left(T_{\max }-T_{\min }\right)^{0.5} G_{0 h}$

$K_{r}$ is an empirical coefficient, which was recommended to be 0.16 for interior regions and 0.19 for coastal regions. In this study $K_{r}$ was locally determined using training data set.

\section{b. H-S-A model}

Annandale et al [23] modified H-S model by introducing correction factor as follow:

$G_{T h}=K_{r}\left(1+2.710^{-5} Z\right)\left(T_{\max }-T_{\min }\right)^{0.5} G_{0 h}$

$Z$ is elevation in $m$ and $K_{r}$ was locally determined.

\section{STATISTICAL ANALYSIS FOR MODEL VALIDATION}

Estimation results validated using statistical parameters. Pearson correlation coefficient was calculated as routine correlation indicator. Residual error was calculated using RMSE (Root Mean Square Error) and presented in NRMSE (Normalized Root Mean Square Error) as follows:

$R M S E=\left[\Sigma\left\{Y_{c}-Y_{0}\right\}^{2} / n\right]^{0.5}$

$N R M S E=R M S E / y_{\max }-y_{\min }$

where, $Y_{c}$ is predicted variable $Y_{0}$ is measured variable, $\mathrm{n}$ is number of data, $y_{\max }$ is maximum measured data $y_{\min }$ is minimum measured data. As an addition, index of agreement was calculated using equation below:

$d=1-\left[\Sigma\left(x_{i}-y_{i}\right)^{2} / \Sigma\left(\left|x_{i}-\bar{x}_{i}\right|+\left|y_{i}-\bar{y}_{i}\right|\right)\right]^{0.5}$

where, $x_{i}$ is predicted variable $y_{i}$ is measured variable, $\bar{x}_{i}$ is averaged predicted variable and $\bar{y}_{i}$ is averaged measured variable.

\section{RESUlTS AND DISCUSSIONS}

Solar radiation estimation has been carried out using Method 1 and Method 2. Both of the methods use decomposition technique to predict beam and diffuse components of global solar radiation. Method 1 uses decision matrix to determine the beam transmittance value. Method 2, which uses correlation, is split into three parts: linear (2a), quadratic (2b) and cubic (2c). Fig. 7 shows scatter plot of measured and predicted value of both the methods.
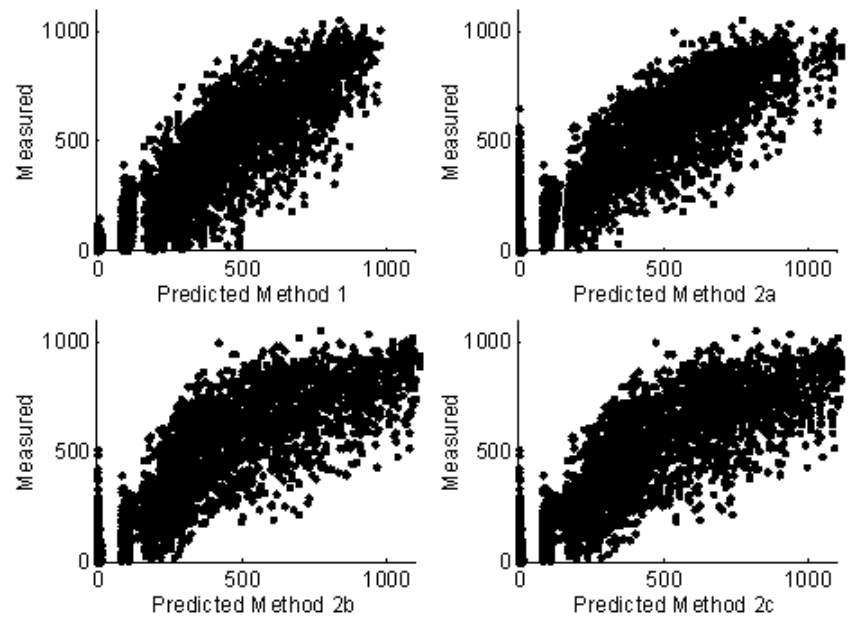

Figure 7: Scatter plot of measured and predicted solar radiation (Method 1)

Table 2 shows statistical analysis results comparison between proposed method and existing temperature based method (Hargreaves and Samani/H-S and Hargreaves, Samani and Annandale/H-S-A). The minimum RMSE value of $87.6 \mathrm{~W} / \mathrm{m}^{2}$ was obtained with 0.95 of correlation coefficient value and 0.97 index of agreement value. Previous method that use precipitation data obtained averaged index of agreement of 0.95 , thus the model presented in this study also performed well. It is concluded from statistical analysis results that Method 1 gives the best estimation results compared to other methods. 
TABLE II. STATISTICAL ANALYSIS RESULTS

\begin{tabular}{|l|c|c|c|c|}
\hline \multirow{2}{*}{ Method } & \multicolumn{4}{c|}{ Statistical parameter } \\
\cline { 2 - 5 } & RMSE & NRMSE & $\mathrm{r}^{a)}$ & $\mathrm{d}^{b)}$ \\
\hline Method 1 & 87.6 & 8.29 & 0.95 & 0.97 \\
\hline Method 2 & & & & \\
- Linear & 101.94 & 9.63 & 0.93 & 0.96 \\
- Quadratic & 109.17 & 10.32 & 0.92 & 0.96 \\
- Cubic & 103.69 & 9.8 & 0.93 & 0.96 \\
\hline H-S method $\left(\mathrm{K}_{\mathrm{r}}=0.175\right)$ & 106.45 & 10.06 & 0.88 & 0.96 \\
\hline H-S-A method $\left(\mathrm{K}_{\mathrm{r}}=0.172\right)$ & 106.44 & 10.06 & 0.88 & 0.96 \\
\hline Note:
\end{tabular}

a) Pearson Correlation Coefficient $\left(\mathrm{r}=\sqrt{\mathrm{R}}^{2}\right)$

b) Index of Agreement

Based on statistical analysis results presented in previous section, Method 1 has been selected to be a better method of solar radiation estimation. Fig. 8 shows example of estimation results of each solar radiation component on random dates using Method 1. Predicted global solar radiation is the total sum of beam and diffuse radiation components.

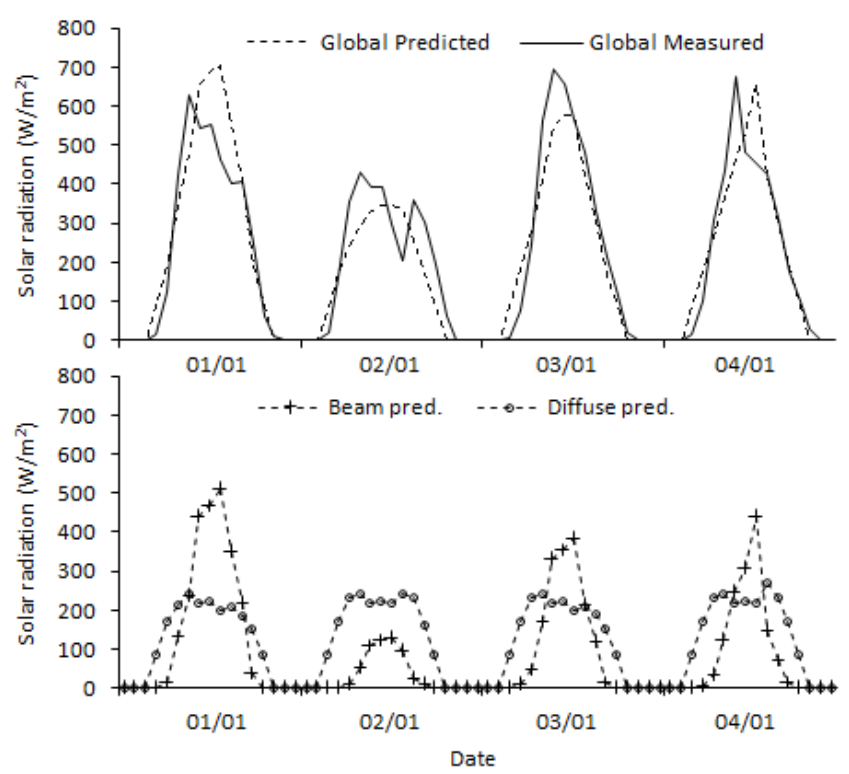

Figure 8: Graphical comparison of predicted (all solar radiation components) and measured solar radiation on random dates using Method 1

Fig. 9 shows graphical comparison of measured and predicted solar radiation for random dates in dry season (a) and rainy season (b). It is observed from Fig. 9 (a) that during the dry season, the solar radiation is high on the most of the day and the estimation results show good compromise with the measured results. Some estimation error are observed from 26-29 May, it is probably caused by cloudy sky which cloud sometimes suddenly come and disappear, whereas the relative humidity and temperature measurement (which were used for estimation) are not as responsive as solar radiation measurement.

More errors are observed from estimation during the rainy season (Fig. 9 (b)). Sometimes the estimation result is overestimating the solar radiation and sometimes underestimates the solar radiation. Again, it is probably caused by the cloudy sky which cloud sometimes suddenly come and disappears. In rainy season, normally the intensity of the cloud is higher than dry season. That is why more errors are observed in rainy season. However, the results using Method 1 are the best compared to the other method and the results are used to fill the missing solar radiation data in this study.

Once, the prediction results of Method 1 have been validated using available data, the results for the missing data days can be used with confidence. Fig. 10 shows prediction results in the days when the solar radiation measurements were absent. There are 23 days missing data in the presented data set and Method 1 was used to estimate solar radiation data during these periods to obtain complete data set.

Although the data filling methodology is good for the location in this study, it also can be utilized for data estimation in other geo-location with notes, for first method the assignment criteria of atmospheric transmittance using $\mathrm{RH}$ and ambient temperature should be adjusted to the available solar radiation data of the area to get minimum error. To generate general criteria of atmospheric transmittance assignment using RH and ambient temperature further research is required with sufficient large amount of data for various area. For the second method, the correlation should be build based on available measurement nearest from the location to give satisfactory estimation results.
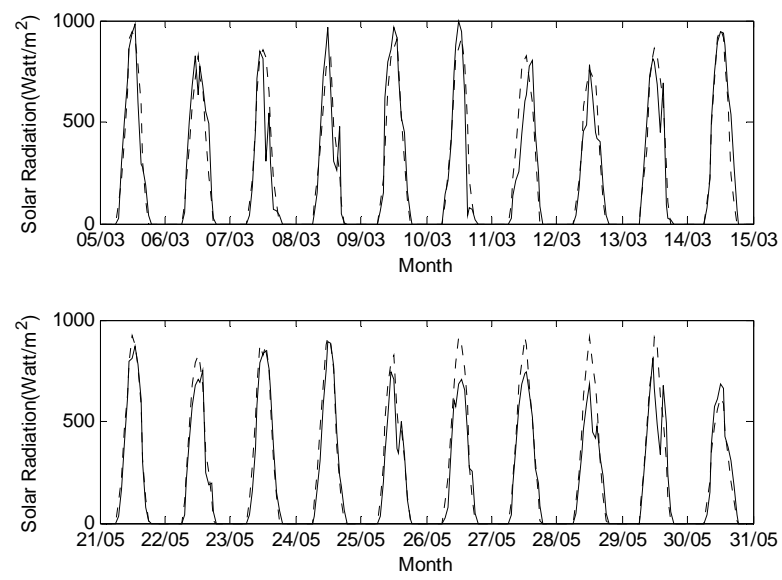

(a) Dry season
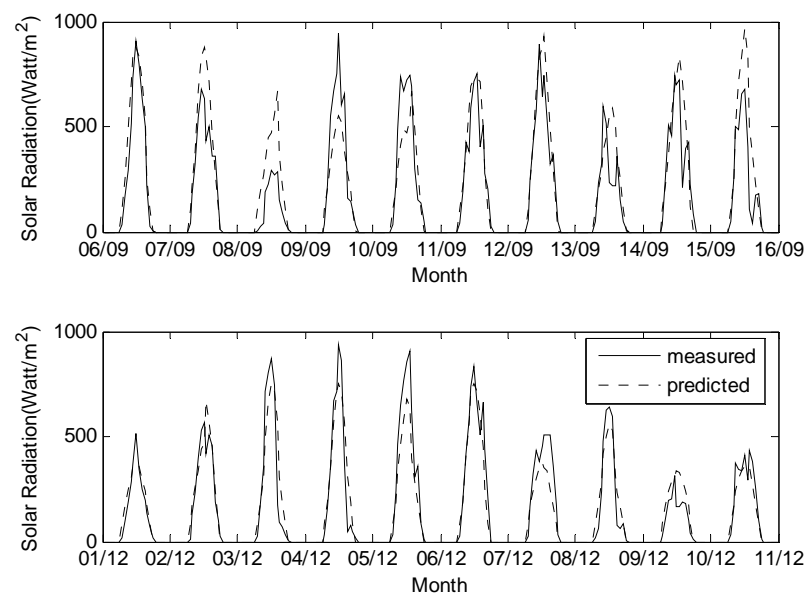

(b) Rainy season

Figure 9: Graphical comparison between measured and predicted solar radiation for random dates (Method 1$)$ 


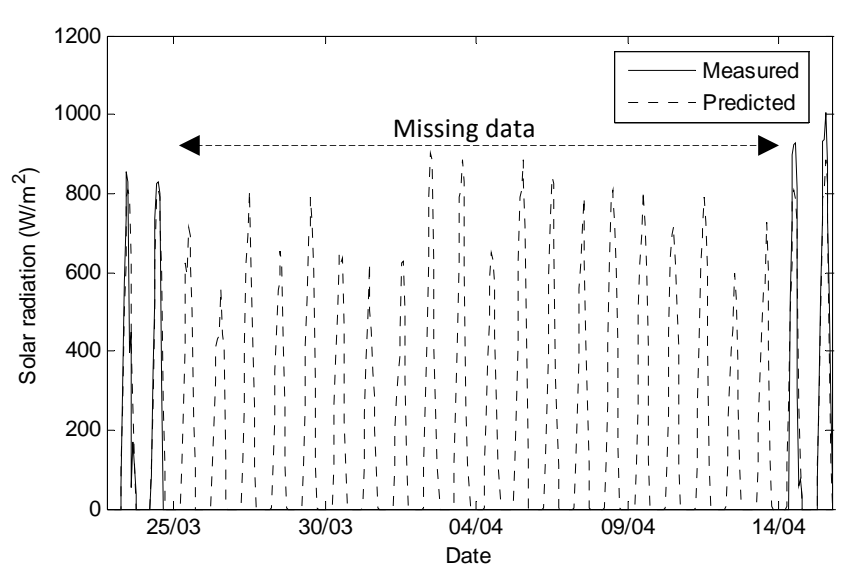

Figure 10: Estimation results of missing measured data on $25 \mathrm{March}-13$ April (Method 1)

\section{CONCLUSIONS}

The prediction of hourly solar radiation data was carried out in this study based on two methods. First method is by using decision matrix from measured $\mathrm{RH}$ and ambient temperature data. The second method is by using RH-clearness index, clearness index-beam atmospheric transmission and beam atmospheric transmission- $\mathrm{RH}$ correlation. The result shows that both methods perform well. Method 1 provided better results with minimum correlation coefficient of 0.95 , RMSE of $87.6 \mathrm{Watt} / \mathrm{m}^{2}$, NRSME of $8.29 \%$ and index of agreement of 0.97 . The prediction was intended to fill missing data in solar radiation data set to get complete time series data. However, in this study only one year of one area data have been used. Validation using sufficient large amount of data is required for wider application of the method.

\section{ACKNOWLEDGMENT}

The authors would like to thank Universiti Teknologi PETRONAS for providing facilities and grant under STIRF schemes No. 63/08.09 for the research.

\section{REFERENCES}

[1] G. S. Campbell and J. M. Norman, "Introduction to Environmental Biophysics. 2nd ed. New York: Springer-Verlag. Pp. 167-183, 1998

[2] Reindl DT, Beckman WA, Duffie JA, "Diffuse fraction correlations", Solar Energy 1990; 45:1-7

[3] F.J. Batlles et al, "Empirical modeling of hourly direct irradiance by means of hourly global irradiance", Energy 25: 675-688, 2000

[4] L.T. Wong and W.K. Chow, "Solar radiation model", Applied Energy 69: 191-224, 2001

[5] F.J. Batlles, M.A. Rubioa, J. Tovarb, F.J. Olmoc and L. Alados-Arboledas, "Empirical modeling of hourly direct irradiance by means of hourly global irradiance", Energy 25: 675-688, 2000

[6] C.A. Gueymard, "Direct solar transmittance and irradiance predictions with broadband models. Part I: detailed theoretical performance assessment", Solar Energy 74: 355-379, 2003

[7] Angström A, "Solar and terrestrial radiation", Q J R Met Soc 50:121-5, 1924

[8] M. Yorukoglu and A.N. Celik, "A critical review on the estimation of daily global solar radiation from sunshine duration", Energy Conversion and Management 47: 2441-2450, 2006

[9] Bristow, K. L. and G. S. Campbell, "On the relationship between incoming solar radiation and daily maximum and minimum temperature", Agric. For. Meteor. 31:159-166, 1984
[10] Hargreaves, G. H. and Z. A. Samani, "Reference crop evapotranspiration from temperature. Appl. Eng. Agric. 1:96-99, 1985

[11] Hunt LA, Kuchar L, Swanton CJ. Estimation of solar radiation for use in crop modelling. Agric. Forest Meteorol. 91(3-4):293-300, 1998

[12] Kurt Spokas and Frank Forcella, "Estimating hourly incoming solar radiation from limited meteorological data", Weed Science, $54: 182-189,2006$

[13] Hunt LA, Kuchar L, Swanton CJ. Estimation of solar radiation for use in crop modelling. Agric. Forest Meteorol. 91(3-4):293-300, 1998

[14] Louche et al, "Correlations for direct normal and global horizontal irradiation on French Mediterranean site", Solar Energy 46: 261-266, 1991

[15] J. A. Duffie, W. A. Beckman, "Solar Engineering of Thermal Processes", third edition, John Wiley \& Sons, Inc., New York, 2006

[16] Liu, B. Y. and R. C. Jordan, "The interrelationship and characteristic distribution of direct, diffuse, and total solar radiation", Sol. Energy 4: $1-19,1960$

[17] Balaras C. A. et al., "On the relationship of beam transmittance on clearness index for Athens, Greece", Int. J. Solar Energy, Vol. 7, pp 171-179, 1989

[18] Sheldon M. Ross, "Introduction to probability and statistics for engineer and scientists". 4th Edition, Academic Press, Elsevier, Canada, 2009

[19] Guofeng Wu, et al. "Methods and strategy for modeling daily global solar radiation with measured meteorological data - A case study in Nanchang station, China", Energy Conversion and Management 48, 2447-2452, 2007

[20] Yang K, Koike T. Estimating surface solar radiation from upper-airhumidity. Solar Energy, 72(2):177-86, 2002

[21] N. Mohan Kumar et al, "An empirical model for estimating hourly solar radiation over the Indian seas during summer monsoon season", Indian Journal of Marine Sciences, Vol. 30, pp 123-131, 2001

[22] GH. Hargreaves and ZA. Samani, "Estimating potential evapotranspiration”, J. Irrg. Drain Eng ASCE 108: 182-190, 1982

[23] JG. Annandale et al, "Software for missing data error analysis of Penman-Monteith reference evapotranspiration", Irrig. Science 21:57-67, 2002

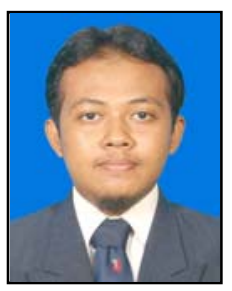

Dimas Firmanda Al Riza is MSc candidate in the Department of Mechanical Engineering in Universiti Teknologi PETRONAS, Bandar Seri Iskandar, Perak, Malaysia. He obtained his B.Sc (Engineering Physics) from Institut Teknologi Sepuluh Nopember, Surabaya, Indonesia.

phone: $+60-10-3770160$

email:dimasfirmanda@yahoo.com

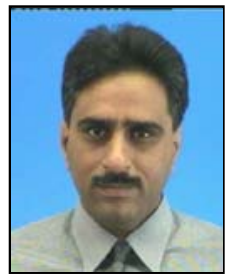

Syed Ihtsham ul Haq Gilani is Senior Lecturer in the Department of Mechanical Engineering in Universiti Teknologi PETRONAS, Bandar Seri Iskandar, Perak, Malaysia. He obtained his B.Sc (Mechanical Engineering) from University of Engineering and Technology Lahore. MSc and Phd (Manufacturing and Mechanical Engineering) from University of Birmingham phone: + 60-5-3687029

email: syedihtsham@petronas.com.my

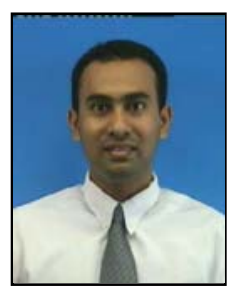

Mohd. Shiraz Aris is Senior Lecturer in the Department of Mechanical Engineering in Universiti Teknologi PETRONAS, Bandar Seri Iskandar, Perak, Malaysia. He obtained his B.Sc (Mechanical Engineering) from North Carolina State University. MSc (Energy Systems and the Environment) from University of Strathclyde and Phd (Heat Transfer Enhancement) from University of Liverpool phone: + 60-5-3687016 email: mshiraz_aris@petronas.com.my 